\title{
Development of Improved Tumor-Residualizing, GRPR- Targeted Agents: Preclinical Comparison of an Endolysosomal Trapping Approach in Agonistic and Antagonistic Constructs
}

\author{
Wenting Zhang*1,2, Wei Fan*1,2, Brendan M. Ottemann ${ }^{3}$, Sameer Alshehri ${ }^{1,2}$, and Jered C. Garrison ${ }^{1,2,4,5}$ \\ ${ }^{I}$ Department of Pharmaceutical Sciences, University of Nebraska Medical Center, Omaha, Nebraska; ${ }^{2}$ Center for Drug Delivery \\ and Nanomedicine, University of Nebraska Medical Center, Omaha, Nebraska; ${ }^{3}$ Department of Pharmacology and Experimental \\ Neuroscience, University of Nebraska Medical Center, Omaha, Nebraska; ${ }^{4}$ Fred and Pamela Buffett Cancer Center, University of \\ Nebraska Medical Center, Omaha, Nebraska; and ${ }^{5}$ Department of Biochemistry and Molecular Biology, University of Nebraska \\ Medical Center, Omaha, Nebraska
}

\begin{abstract}
Receptor-targeted radiopharmaceuticals based on low-molecularweight carriers offer many clinically advantageous attributes relative to macromolecules but have generally been hampered by their rapid clearance from tumors, thus diminishing tumor-to-nontarget tissue ratios. Herein, we present a strategy using irreversible inhibitors (E-64 derivative) of cysteine cathepsins (CCs) as trapping agents to increase the tumor retention of receptor-targeted agents. Methods: We incorporated these CC-trapping agents into agonistic and antagonistic pharmacophores targeting the gastrin-releasing peptide receptor (GRPR). The synthesized radioconjugates with either an incorporated $\mathrm{CC}$ inhibitor or a matching control were examined using in vitro and in vivo models of the GRPR-positive, PC-3 human prostate cancer cell line. Results: From the in vitro studies, multiple techniques confirmed that the CC-trapping, GRPR-targeted constructs were able to increase cellular retention by forming intracellular macromolecule adducts. In PC-3 tumor-bearing xenograft mice, the CC-trapping, GRPR-targeted agonistic and antagonistic constructs led to an approximately 2 -fold increase in tumor retention with a corresponding improvement in most tumor-to-nontarget tissue ratios over $72 \mathrm{~h}$. Conclusion: CC endolysosomal trapping provides a pathway to increase the efficacy and clinical potential of low-molecularweight, receptor-targeted agents.
\end{abstract}

Key Words: GRPR-targeted peptides; agonists and antagonists; cysteine cathepsin inhibitor; SPECT/CT

J Nucl Med 2020; 61:443-450

DOI: 10.2967/jnumed.119.231282

$\mathbf{T}$ he elevated expression of the gastrin-releasing peptide receptor (GRPR) in prostate and other cancers has prompted the development of GRPR-targeted diagnostic and therapeutic agents (1). Most GRPR-targeted agents use the C-terminal fragment of the bombesin peptide because of its ability to target the receptor with nanomolar affinity $(2,3)$. Examination of the structure-activity profile of this

Received May 31, 2019; revision accepted Sep. 9, 2019.

For correspondence or reprints contact: Jered C. Garrison, University of Nebraska Medical Center, 985830 Nebraska Medical Center, DRC1 Room 4008, Omaha, NE 68198.

E-mail: jcgarrison@unmc.edu

${ }^{*}$ Contributed equally to this work.

Published online Oct. 10, 2019.

COPYRIGHT (c) 2020 by the Society of Nuclear Medicine and Molecular Imaging. fragment has revealed numerous highly GRPR-binding derivatives with different pharmacologic profiles in terms of agonistic versus antagonistic character (4-6). Exceptional work by Maecke's group and others has identified antagonistic analogs (e.g., RM26) that have substantially higher tumor uptake and better nontarget clearance profiles than agonistic analogs (7-9). Despite encouraging clinical and preclinical results $(10,11)$, the relatively short tumor residence time of low-molecular-weight constructs such as GRPR-targeted peptides still represents a translational hurdle, particularly with regard to radiotherapeutic uses (12).

To overcome this limitation, chemical approaches have been explored to enhance the tumor retention (i.e., residualization) of low-molecular-weight, receptor-targeted agents (13-16). One of the approaches our laboratory has examined involves cysteine cathepsins (CCs), a family of endolysosomal proteases that are expressed predominately in endolysosomal vesicles and are associated with protein turnover within the cell $(17,18)$. Incorporation of irreversible CC inhibitors (e.g., E-64 (19,20)) into the receptor-targeted construct results in the formation of high-molecular-weight adducts within the endolysosomal compartments of cancer cells, resulting in substantially enhanced retention of the receptor-targeted agent.

Here, for the first time to our knowledge, the CC residualization approach was explored using the well-validated, GRPR-targeted agonistic and antagonistic constructs $\mathrm{BBN}(7-14) \mathrm{NH}_{2}$ (Gln-TrpAla-Val-Gly-His-Leu-Met-NH2) and RM26 (D-Phe-Gln-Trp-AlaVal-Gly-His-Sta-Leu- $\mathrm{NH}_{2}$ ), respectively. By examining the agonistic and antagonistic pair, we mechanistically evaluated whether, as we suspected, internalization is key to the efficient formation of highly retained $\mathrm{CC}$ adducts leading to increased tumor retention. Specifically, we synthesized an analog of E-64, a well-known irreversible CC inhibitor, and incorporated this moiety into the structure of agonistic and antagonistic GRPR-targeted constructs (Fig. 1). We defined the nomenclature of these conjugates as follows: GRPR-targeted agonist (AG), GRPR-targeted antagonist $(\mathrm{AN})$, active inhibitor (E), and inactive inhibitor (C). Following this nomenclature yields the GRPR-targeted agonists E-AG and $\mathrm{C}-\mathrm{AG}$ and the antagonists E-AN and C-AN. The biologic performance of these analogs was examined using in vitro and in vivo human prostate cancer PC-3 cell models. The results reveal interesting mechanistic insights concerning the generality of our $\mathrm{CC} /$ endolysosomal trapping approach and provide a better understanding of the endocytic profile of RM26 and perhaps other GRPRtargeted antagonistic peptides. 


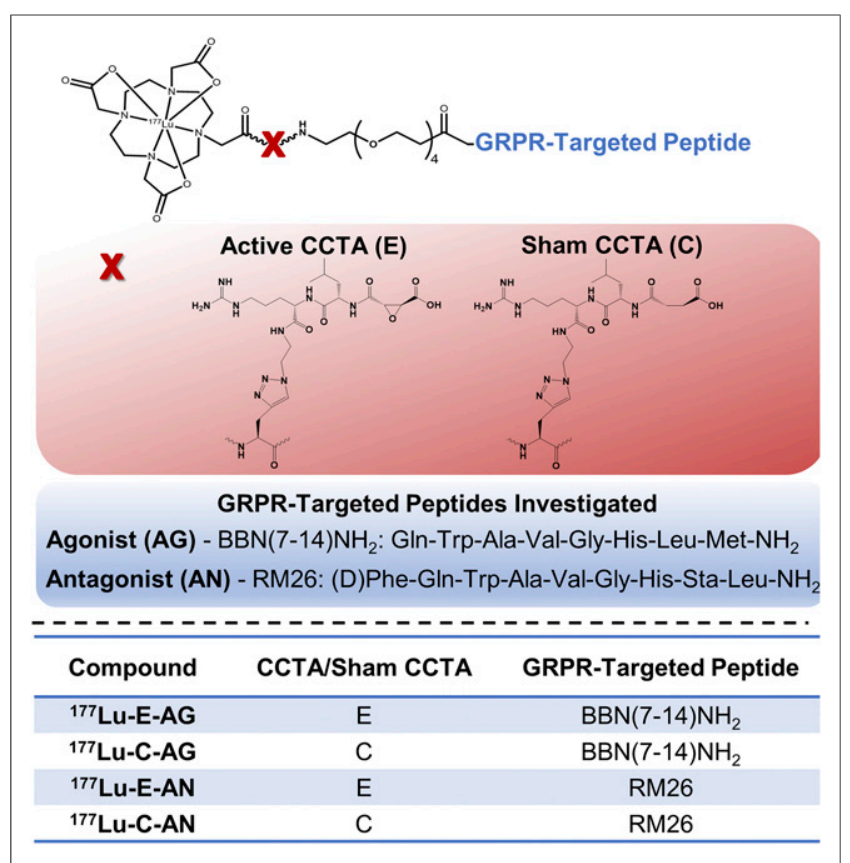

FIGURE 1. Structure of GRPR-targeted peptides incorporated with $\mathrm{CC}$ inhibitor and its matching control. BBN = bombesin; CCTA = CCtrapping agent.

\section{MATERIALS AND METHODS}

The supplemental materials (available at http://jnm.snmjournals.org) provide our methodologies concerning chemical characterization (Supplemental Scheme 1) and peptide synthesis characterization (Supplemental Table 1; Supplemental Figs. 1-4). Experiments involving distribution coefficient studies, peptide metabolic stability studies, inhibition of cathepsin B (CatB) activity, and determination of the inhibition constant $\left(K_{i}\right)$ of the conjugates to CatB and cellular trafficking studies were performed according to published methods $(13,14)$.

\section{Cell Lines and Animals}

Prostate cancer cell lines (PC-3) were obtained from American Type Culture Collection, cultured in Ham F-12K medium (Gibco, Life Technologies) supplemented with $10 \%$ fetal bovine serum, and grown as monolayers at $37^{\circ} \mathrm{C}$ in a humidified atmosphere containing $5 \%$ $\mathrm{CO}_{2}$. The GRPR expression of our PC-3 cells $\left(3.5 \times 10^{5}\right.$ receptors/ cell) has been evaluated and reported elsewhere (21).

Four-week-old severe combined immunodeficiency (SCID) (NOD.CB17-Prkdc ${ }^{\text {scid }}$ ) mice were obtained from The Jackson Laboratory. Food and water were given ad libitum. Five mice per group were kept in the same cage with an air filter cover under light- and temperature-controlled conditions before experiments. On the day of the experiment, each animal was kept in an individual cage with identical housing conditions. The animals were treated in accordance with the principles of animal care outlined by the National Institutes of Health and approved by the Institutional Animal Care and Use Committee of the University of Nebraska Medical Center.

\section{Radiolabeling}

${ }^{177} \mathrm{LuCl}_{3}(0.2 \mathrm{nmol}, 37 \mathrm{MBq})$ (U.S. Department of Energy) was mixed with $25-\mu \mathrm{g}$ samples in sodium acetate buffer $(0.5 \mathrm{M}, 120 \mu \mathrm{L}, \mathrm{pH} 5.5)$ and incubated at $85^{\circ} \mathrm{C}$ for $20 \mathrm{~min}$. The mixture was purified by highperformance liquid chromatography. To remove organic eluent, the ${ }^{177} \mathrm{Lu}-$ labeled conjugate was loaded onto an Empore (CDS Analytical) C18 high-performance extraction cartridge followed by washing with water $(2 \times 3 \mathrm{~mL})$ and elution by an ethanol/saline solution $(\mathrm{v} / \mathrm{v}=6: 4,150 \mu \mathrm{L})$.

\section{In Vitro Studies}

Competitive binding studies were performed as previously described (22). For these studies, ${ }^{177} \mathrm{Lu}$-DOTA-SP714 $\left({ }^{177} \mathrm{Lu} \text {-DOTA-(D-Ser }\right)_{5^{-}}$ $\mathrm{PEG}_{3}$-Gln-Trp-Ala-Val-Gly-His-Leu-Met-NH $\left.{ }_{2}\right)(0.18$ pmol, 28.7 kBq $)$ served as the competitive radioligand.

Internalization and efflux studies on the ${ }^{177} \mathrm{Lu}$-labeled conjugates $(0.18 \mathrm{pmol}, 28.7 \mathrm{kBq})$ were performed as previously detailed (23). The only modification made was to the efflux protocol for the antagonist constructs, in which acid washing of the cells was performed to remove surface-bound activity at the initial $(0 \mathrm{~h})$ time point. This washing was not undertaken for the agonist constructs because of the low surfacebound activity of these agents.

The conjugates (E-AG and E-AN) were labeled with ${ }^{\text {nat }} \mathrm{EuCl}_{3}$ as described before (Supplemental Fig. 5) (14). For confocal trafficking studies, briefly, in a 4-well Lab-Tek chambered coverglass disk (ThermoFisher), PC-3 cells (3,000/well) were incubated with the natEu-labeled conjugate $(5 \mu \mathrm{M})$ in the presence of LysoTracker Green $(100 \mathrm{nM}$; Molecular Probes, Inc.) at $37^{\circ} \mathrm{C}$ for $4 \mathrm{~h}$. Cells were subsequently washed with fresh medium and imaged at the desired time points.

To examine in vitro adduct formation, the radioconjugates (4.5 pmol, $0.7 \mathrm{MBq}$ ) were incubated with $\mathrm{CatB}$ (human liver) $(3 \mathrm{nM}, 10$ $\mu \mathrm{L})$ (Millipore Sigma) or with PC-3 $\left(1 \times 10^{6}\right)$ cells. The detailed protocols for the workup and the autoradiographic sodium dodecyl sulfate-polyacrylamide gel electrophoresis (SDS-PAGE) and centrifugal filtration analyses were as previously outlined $(13,14)$. Blocking studies were performed by incubation with the CA-074 inhibitor (ApexBio) $(10 \mu \mathrm{M}, 10 \mu \mathrm{L})$ or an excess of unlabeled E-AG or E-AN $(40 \mu \mathrm{M})$.

\section{Biodistribution and Renal Blocking Studies}

Male SCID mice (6 wk old) received subcutaneous injections of 100 $\mu \mathrm{L}$ of PC-3 cells $\left(5 \times 10^{6}\right)$ suspended in Matrigel (Corning) into the flanks. When the tumor diameter reached $5 \mathrm{~mm}$, the mice were randomly grouped and intravenously injected with $100 \mu \mathrm{L}$ of purified ${ }^{177} \mathrm{Lu}$-labeled conjugates (2.3 pmol, 0.4 MBq). Renal blocking studies were performed by a $40 \mathrm{mg} / \mathrm{kg}$ intravenous injection of D-lysine (Alfa Aesar), a 4-h prophylactic $1 \mathrm{mg} / \mathrm{kg}$ intraperitoneal injection of colchicine (Alfa Aesar) (24), or a combination of these two. The mice were sacrificed at the desired time point. Blood, tumor, and other excised tissues were weighed, and the radioactivity for each sample was measured using a $\gamma$-counter. The percentage injected dose per gram $(\% \mathrm{ID} / \mathrm{g})$ was calculated.

\section{SPECT/CT Imaging}

${ }^{177} \mathrm{Lu}$-labeled conjugates $(0.2 \mathrm{nmol}, 37 \mathrm{MBq})(100 \mu \mathrm{L})$ were injected intravenously into PC-3 tumor-bearing mice. At predetermined time points $(4,24$, and $72 \mathrm{~h}$ after injection), mice were anesthetized with isoflurane. SPECT/CT images were acquired and analyzed as previously described (22).

\section{In Vivo Adduct Formation Studies}

The radioconjugates $(0.18 \mathrm{nmol}, 30 \mathrm{MBq})$ were intravenously injected into PC-3 tumor-bearing mice. The mice were sacrificed at $24 \mathrm{~h}$ after injection, and the tumor, pancreas, liver, and kidney were excised, homogenized, and centrifuged to remove the pellet. An aliquot $(18 \mu \mathrm{L})$ of the supernatant was examined by autoradiographic SDSPAGE as described before (14). An additional aliquot $(80 \mu \mathrm{L})$ of the supernatant was analyzed by centrifugal filtration (molecular weight cutoff, $10 \mathrm{kDa}$ ) to separate macromolecule-associated radioactivity from low-molecular-weight radioactivity. The radioactivity in each fraction was quantified using a $\gamma$-counter to calculate the percentage of adduct formation.

\section{Statistical Analysis}

Half-maximal inhibitory concentration $\left(\mathrm{IC}_{50}\right)$ and $K_{i}$ were determined by nonlinear regression using GraphPad Prism 5. Comparisons for the internalization and efflux studies, cellular trafficking studies, in vitro and 
in vivo adduct formation studies, biodistribution studies, and renal blocking studies were analyzed by the 2-tailed Student $t$ test, and a $P$ value of less than 0.05 was considered statistically significant.

\section{RESULTS}

\section{Synthesis and Characterization of Endolysosome-Trapped GRPR-Targeted Agents}

The structures of the synthesized experimental and control GRPR-targeted analogs are depicted in Figure 1. For our inactive control, succinic acid was used instead of the epoxide moiety. With only the deletion of the oxygen, this inactive control (i.e., no CC inhibition/adduct formation) retains high structural similarity to the active inhibitor. These conjugates were labeled with ${ }^{177} \mathrm{LuCl}_{3}$ to achieve a radiolabeling efficiency that ranged from $71.5 \%$ to $84.0 \%$ (Supplemental Fig. 6). Peptide metabolic stability studies in human serum demonstrated that $36.8 \%, 36.6 \%$, $30.0 \%$, and $20.9 \%$ of ${ }^{177} \mathrm{Lu}-\mathrm{E}-\mathrm{AG},{ }^{177} \mathrm{Lu}-\mathrm{C}-\mathrm{AG},{ }^{177} \mathrm{Lu}-\mathrm{E}-\mathrm{AN}$, and ${ }^{177} \mathrm{Lu}-\mathrm{C}-\mathrm{AN}$, respectively, were intact at $24 \mathrm{~h}$ (Supplemental Fig. 7). All unlabeled analogs demonstrated good hydrophilicity, with nanomolar binding affinities $\left(\mathrm{IC}_{50}, 16-24 \mathrm{nM}\right)$ for the GRPR (Table 1).

\section{CatB Inhibition}

The inhibitory potency of the conjugates against CatB was examined, and the $\mathrm{IC}_{50}$ and $K_{i}$ values are provided (Table 1; Supplemental Figs. 8 and 9). E-AG and E-AN demonstrated nanomolar $\mathrm{IC}_{50}$ values for $\mathrm{CatB}$, whereas the corresponding inactive controls had no inhibition of the protease over the concentration range investigated. The determined $K_{i}$ values for E-AG and E-AN were approximately 9-fold higher than the $15 \pm 1 \mathrm{nM}$ inhibition value obtained for the active inhibitor (no peptide attached). Overall, in the context of our intended application, the peptide exhibited only a modest influence on the activity of the inhibitor.

\section{In Vitro Internalization, Efflux, and Cellular Trafficking Studies}

By $4 \mathrm{~h}$, the internalization rate of the two agonistic conjugates, $13.5 \%$ and $13.2 \%$ for ${ }^{177} \mathrm{Lu}-\mathrm{E}-\mathrm{AG}$ and ${ }^{177} \mathrm{Lu}-\mathrm{C}-\mathrm{AG}$, correspondingly, far outpaced the antagonistic analogs, $1.7 \%$ and $1.8 \%$ for ${ }^{177} \mathrm{Lu}-\mathrm{E}-\mathrm{AN}$ and ${ }^{177} \mathrm{Lu}-\mathrm{C}-\mathrm{AN}$ (Fig. 2A). The percentage of surface-bound radioactivity for the two antagonists was nearly 2-fold higher than the corresponding internalized signal, demonstrating that the RM26-based antagonists do not efficiently-relative to the agonists-induce receptor-mediated internalization. With respect to efflux, ${ }^{177} \mathrm{Lu}-\mathrm{E}-\mathrm{AG}$ demonstrated higher retention, with only $38.8 \%$ externalization by $24 \mathrm{~h}$, compared with $54.3 \%$ for ${ }^{177} \mathrm{Lu}-\mathrm{C}-\mathrm{AG}(P<0.01)$ (Fig. $\left.2 \mathrm{~B}\right)$. However, ${ }^{177} \mathrm{Lu}$-antagonists demonstrated sustainably higher efflux percentages, likely caused by reduced rates of internalization and adduct formation. Nevertheless, at $24 \mathrm{~h},{ }^{177} \mathrm{Lu}-\mathrm{E}-\mathrm{AN}(53.5 \%)$ exhibited a lower efflux rate than ${ }^{177} \mathrm{Lu}-\mathrm{C}-\mathrm{AN}(61.8 \%)(P<0.0001)$ (Fig. 2B). Cell-trafficking studies using confocal microscopy (Supplemental Fig. 10) demonstrated that the Europium-labeled conjugate Eu-E-AG gave higher retention (1.8-fold at $24 \mathrm{~h}$ ) than Eu-C-AG. At $24 \mathrm{~h}, 93 \%$ of the signal from Eu-E-AG colocalized with the endolysosomal compartments, compared with $70 \%$ for Eu-C-AG.

\section{In Vitro Adduct Studies}

Using autoradiographic SDS-PAGE, the ability of the radioconjugates to form adducts with CCs was established (Fig. 3). Incubation of ${ }^{177} \mathrm{Lu}-\mathrm{E}-\mathrm{AG}$ and ${ }^{177} \mathrm{Lu}-\mathrm{E}-\mathrm{AN}$ with $\mathrm{CatB}$ produced bands with a molecular weight of around $27 \mathrm{kDa}$, corresponding to the heavy chain of CatB (Fig. 3A). Coincubation with CA-074, a commercial CatB-selective inhibitor, completely abolished the ability of ${ }^{177} \mathrm{Lu}-\mathrm{E}-\mathrm{AG}$ and ${ }^{177} \mathrm{Lu}-\mathrm{E}-\mathrm{AN}$ to form adducts, indicating that these conjugates bind to the same active site.

Exposure of PC-3 cells to the radioconjugates for $24 \mathrm{~h}$ and analysis of the lysate by SDS-PAGE demonstrated that ${ }^{177} \mathrm{Lu}-\mathrm{E}-\mathrm{AG}$ and ${ }^{177} \mathrm{Lu}-\mathrm{E}-\mathrm{AN}$ were capable of $\mathrm{CC}$ adduct formation, in contrast to the controls (Fig. 3B). Adduct formation of the adduct-capable radioconjugates was eliminated when a GRPR-blocking agent was added (Fig. 3C), implying that receptor-mediated internalization is key for efficient cellular adduct formation. Lastly, the timedependent cellular retention of ${ }^{177} \mathrm{Lu}-\mathrm{E}-\mathrm{AG}$ and ${ }^{177} \mathrm{Lu}-\mathrm{E}-\mathrm{AN}$ was investigated (Fig. 3D). ${ }^{177} \mathrm{Lu}-\mathrm{E}-\mathrm{AG}$ demonstrated strong and similar adduct formation bands at 2 and $4 \mathrm{~h}$, decreasing by $13.8 \%$ at $24 \mathrm{~h}$. Interestingly, ${ }^{177} \mathrm{Lu}$-E-AN gave its weakest bands at $2 \mathrm{~h}$, and these bands progressively strengthened by $31.5 \%$ over $24 \mathrm{~h}$. This finding may be attributed to slow internalization of the surface-bound antagonists. Analysis of the PC-3 cellular lysate at $24 \mathrm{~h}$ by centrifugal filtration revealed that $80.0 \% \pm 0.9 \%$ and $72 \% \pm 7 \%$ of the internalized radioactivity of ${ }^{177} \mathrm{Lu}-\mathrm{E}-\mathrm{AG}$ and ${ }^{177} \mathrm{Lu}-\mathrm{E}-\mathrm{AN}$, respectively, was associated with macromolecules. These percentages were substantially higher than the $11.5 \% \pm 0.8 \%$ and $53 \% \pm 2 \%$ for the corresponding control radioconjugates. The relatively high radioactivity measured for ${ }^{177} \mathrm{Lu}-\mathrm{C}-\mathrm{AN}$ suggests that the antagonist is somehow associated with the macromolecules in the lysate. Attempts were made to use an aqueous/organic solvent mixture

TABLE 1

Characterization, GRPR Binding Affinity, and CatB Inhibition Activity of Conjugates

\begin{tabular}{|c|c|c|c|c|c|c|}
\hline \multirow[b]{2}{*}{ Analog } & \multirow[b]{2}{*}{ Molecular formula } & \multirow[b]{2}{*}{ LogD (pH 7.4) } & \multirow[b]{2}{*}{ GRPR IC $_{50}(\mathrm{nM})$} & \multirow[b]{2}{*}{ CatB inhibition $\mathrm{IC}_{50}(\mathrm{nM})$} & \multicolumn{2}{|c|}{ CatB inhibition } \\
\hline & & & & & $K_{\mathrm{i}}(\mathrm{nM})$ & $k_{\mathrm{i}} / K_{\mathrm{i}}\left(\mathrm{s}^{-1} \cdot \mathrm{M}^{-1}\right)$ \\
\hline$E-A G$ & $\mathrm{C}_{93} \mathrm{H}_{148} \mathrm{~N}_{28} \mathrm{O}_{28} \mathrm{~S}$ & $-3.13 \pm 0.03$ & $18 \pm 4$ & $26 \pm 4$ & $153 \pm 17$ & $89,000 \pm 3,000$ \\
\hline C-AG & $\mathrm{C}_{93} \mathrm{H}_{150} \mathrm{~N}_{28} \mathrm{O}_{27} \mathrm{~S}$ & $-3.35 \pm 0.09$ & $16 \pm 3$ & $>1,000$ & $一^{\star}$ & $一^{*}$ \\
\hline E-AN & $\mathrm{C}_{105} \mathrm{H}_{163} \mathrm{~N}_{29} \mathrm{O}_{30}$ & $-2.31 \pm 0.18$ & $20 \pm 3$ & $31 \pm 6$ & $107 \pm 11$ & $68,000 \pm 8,000$ \\
\hline C-AN & $\mathrm{C}_{105} \mathrm{H}_{165} \mathrm{~N}_{29} \mathrm{O}_{29}$ & $-1.90 \pm 0.14$ & $24 \pm 4$ & $>1,000$ & - $^{\star}$ & - $^{*}$ \\
\hline
\end{tabular}

${ }^{\star}$ No inhibition was observed in concentration range examined.

Data are mean $\pm \mathrm{SD}(n=3)$. $\log \mathrm{D}_{7.4}$ values were obtained using ${ }^{177} \mathrm{Lu}$-labeled conjugates. Inhibition constants were obtained at $37^{\circ} \mathrm{C}$ and $\mathrm{pH} 5.8$ with human liver CatB.

$K_{\mathrm{i}}=$ the inhibition constants; $K_{\mathrm{i}}=$ the maximum inhibition rate. 


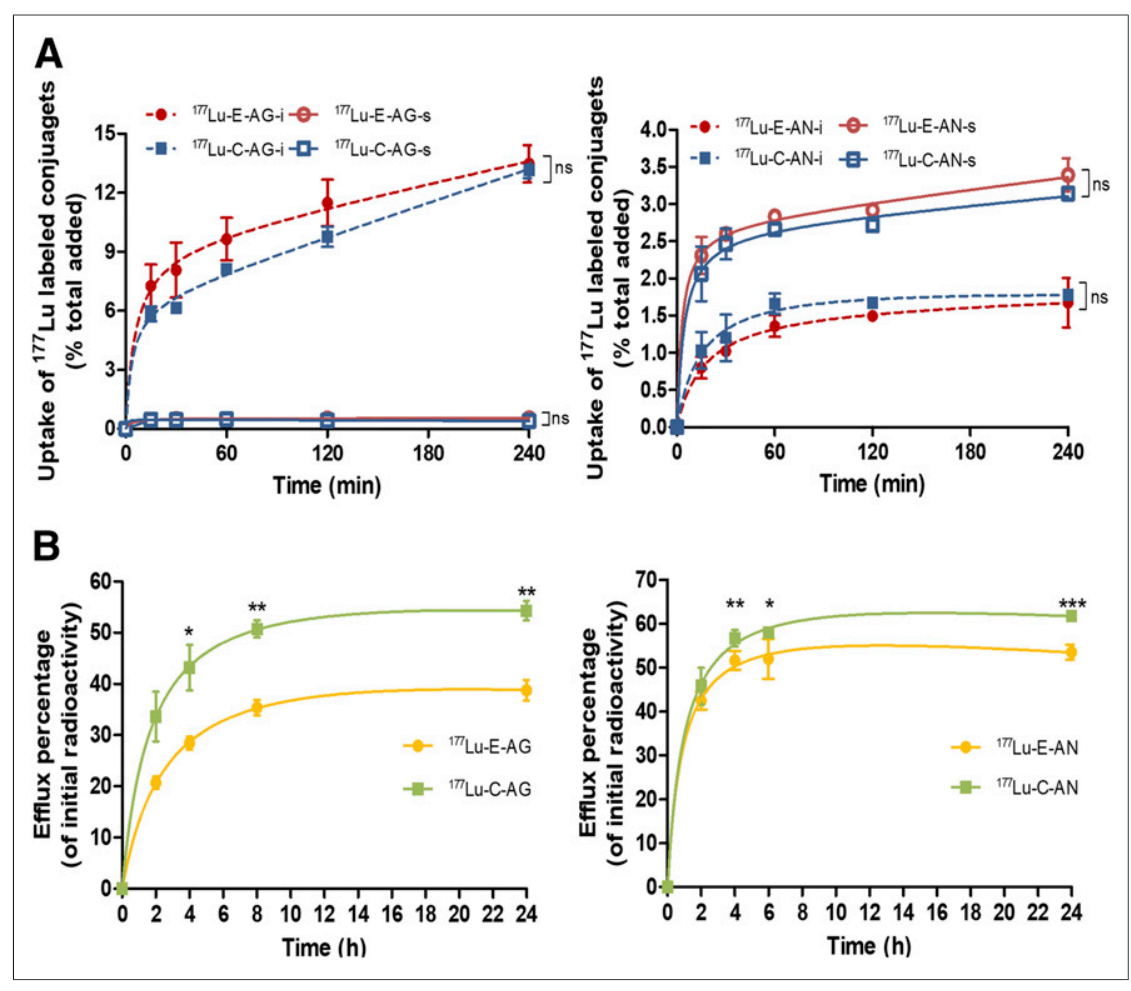

FIGURE 2. (A) Surface-bound (s) and internalization (i) assays for ${ }^{177} \mathrm{Lu}$-labeled conjugates in PC- 3 cells. (B) Efflux assays for ${ }^{177}$ Lu-labeled conjugates in PC- 3 cells. Values are mean \pm SD $(n=3) .{ }^{\star} P<0.05 .{ }^{* \star} P<0.01 .{ }^{\star \star \star} P<0.001$.

(20\% $\mathrm{CH}_{3} \mathrm{CN}, 60 \% \mathrm{MeOH}$, and $20 \%$ phosphate-buffered saline) to reduce nonspecific associations, but the results remained unchanged. The reason for the high macromolecule association for ${ }^{177} \mathrm{Lu}-\mathrm{C}-\mathrm{AN}$ is as yet unknown.

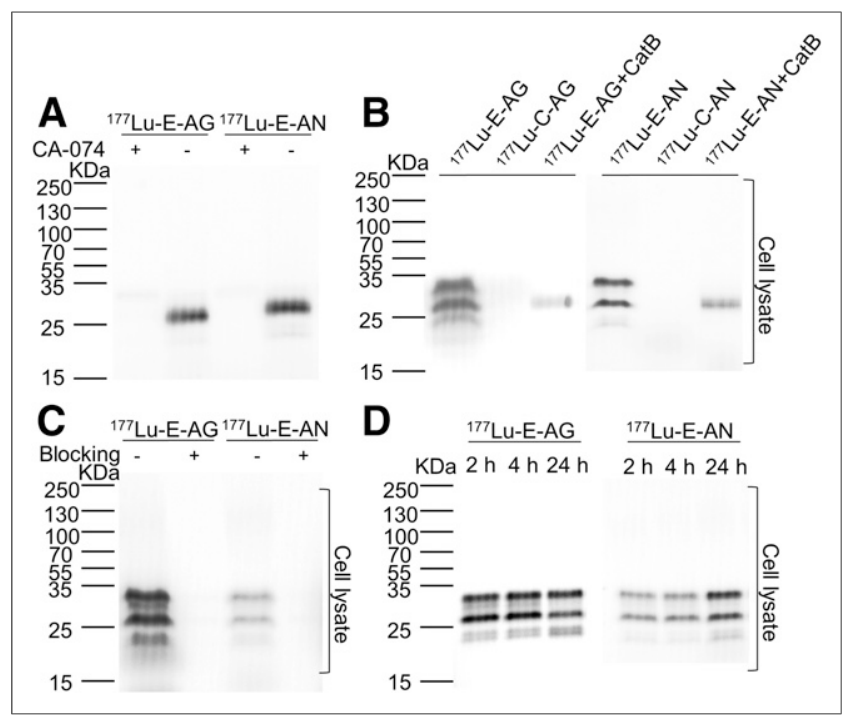

FIGURE 3. Examination of adduct formation using autoradiographs of SDS-PAGE gels. (A) Adduct formation using CatB with or without blocking by cysteine protease inhibitor CA-074. (B) Adducts observed when incubated with PC-3 cells for $24 \mathrm{~h}$ (reference, ${ }^{177} \mathrm{Lu}-\mathrm{E}-\mathrm{AG} / \mathrm{E}-\mathrm{AN}$ with CatB). (C) GRPR-blocking study examining impact on adduct formation (blocking agent, unlabeled E-AG or E-AN). (D) Time-dependent adduct formation in PC-3 cells.

\section{Biodistribution and Renal \\ Blocking Studies}

In vivo biodistribution studies of ${ }^{177} \mathrm{Lu}-$ E-AG, ${ }^{177} \mathrm{Lu}-\mathrm{C}-\mathrm{AG},{ }^{177} \mathrm{Lu}-\mathrm{E}-\mathrm{AN}$, and ${ }^{177} \mathrm{Lu}-\mathrm{C}-$ AN were investigated (Table 2; Supplemental Table 2) in a PC-3 xenograft mouse model. The kidneys were the site of highest nontarget, non-GRPR-mediated uptake. The initial renal uptake for ${ }^{177} \mathrm{Lu}-\mathrm{E}-\mathrm{AG}$ and ${ }^{177} \mathrm{Lu}-\mathrm{E}-\mathrm{AN}$ was $10 \pm 3$ and $7.4 \pm$ $0.9 \% \mathrm{ID} / \mathrm{g}$, respectively. This was higher than the matching control analogs, which had corresponding initial uptake values of $6 \pm 2(P<0.05)$ and $5.4 \pm 1.7(P<0.05)$ $\%$ ID/g. By 72 h, ${ }^{177}$ Lu-E-AG showed significantly higher retention $(68.0 \%$ of the $4-\mathrm{h}$ uptake value $(P=0.05))$ than ${ }^{177} \mathrm{Lu}-\mathrm{C}-\mathrm{AG}$ (18.4\% of the 4 -h uptake $(P<0.01))$. Similar findings were seen with the antagonistic constructs. At the 72-h time point, $49.9 \%$ $(P=0.01)$ and $13.1 \%(P<0.01)$ of the initial uptake for ${ }^{177} \mathrm{Lu}-\mathrm{E}-\mathrm{AN}$ and ${ }^{177} \mathrm{Lu}-\mathrm{C}-\mathrm{AN}$ were retained. The elevated renal retention of the GRPR-targeted constructs containing the active inhibitor prompted us to examine the potential of renal blocking agents. To that end, the renal blocking effect of Dlysine and colchicine were investigated for ${ }^{177} \mathrm{Lu}-\mathrm{E}-\mathrm{AN}$ (Fig. 4A; Supplemental Table 3; Supplemental Fig. 11) at 4 and $24 \mathrm{~h}$. At $24 \mathrm{~h}$, D-lysine, colchicine, and a combination of the blocking agents demonstrated a $27.4 \%(P=0.044), 55.7 \%(P=$ $0.0047)$, and $48.3 \%$ ( $P=0.0052)$ inhibition of renal uptake for ${ }^{177} \mathrm{Lu}-\mathrm{E}-\mathrm{AN}$. Neither agent affected the tumor uptake of ${ }^{177} \mathrm{Lu}-$ E-AN at either time point (Fig. 4B).

At $4 \mathrm{~h}$, the tumor uptake of ${ }^{177} \mathrm{Lu}-\mathrm{E}-\mathrm{AG}(3.3 \pm 1.1 \% \mathrm{ID} / \mathrm{g})$ and ${ }^{177} \mathrm{Lu}-\mathrm{C}-\mathrm{AG}(2.9 \pm 0.4 \% \mathrm{ID} / \mathrm{g})$ were statistically identical. By $24 \mathrm{~h}$, retention of the initial uptake for ${ }^{177} \mathrm{Lu}-\mathrm{E}-\mathrm{AG}$ was $89.9 \%$, whereas that for ${ }^{177} \mathrm{Lu}-\mathrm{C}-\mathrm{AG}$ decreased significantly to $64.3 \%(P<0.01)$. At $72 \mathrm{~h}, 62.8 \%(2.06 \pm 0.16 \% \mathrm{ID} / \mathrm{g})$ of the initial uptake for ${ }^{177} \mathrm{Lu}-\mathrm{E}-\mathrm{AG}$ was retained, whereas ${ }^{177} \mathrm{Lu}-\mathrm{C}-\mathrm{AG}$ exhibited only $32.9 \%(0.94 \pm 0.14 \% \mathrm{ID} / \mathrm{g})$ retention $(P<$ $0.0001)$. Overall, ${ }^{177} \mathrm{Lu}-\mathrm{E}-\mathrm{AG}$ yielded 2.2 -fold higher tumor retention than ${ }^{177} \mathrm{Lu}-\mathrm{C}-\mathrm{AG}$ at $72 \mathrm{~h}(P<0.0001)$. Similar retention profiles for these two radioconjugates were observed in the mouse pancreas, which is a well-established GRPR-positive tissue (25).

For ${ }^{177} \mathrm{Lu}-\mathrm{E}-\mathrm{AN}$ and ${ }^{177} \mathrm{Lu}-\mathrm{C}-\mathrm{AN}$, initial PC-3 tumor uptake was considerably higher than that for the agonists, with statistically identical values of $11.9 \pm 1.7$ and $13 \pm 3 \% \mathrm{ID} / \mathrm{g}$, respectively. By $24 \mathrm{~h}$, the tumor retention of ${ }^{177} \mathrm{Lu}-\mathrm{E}-\mathrm{AN}$ and ${ }^{177} \mathrm{Lu}-\mathrm{C}-\mathrm{AN}$ was $53.2 \%(P=0.0008)$ and $28.9 \%(P=0.0008)$, respectively, of the 4-h values. At $72 \mathrm{~h},{ }^{177} \mathrm{Lu}-\mathrm{E}-\mathrm{AN}$ and ${ }^{177} \mathrm{Lu}-\mathrm{C}-\mathrm{AN}$ had retention values of $31.9 \%(P<0.0001)$ and $14.7 \%(P=0.0003)$ of the initial uptake. The 2-fold increase in tumor retention of ${ }^{177} \mathrm{Lu}-\mathrm{E}-$ AN, compared with ${ }^{177} \mathrm{Lu}-\mathrm{C}-\mathrm{AN}$, at $72 \mathrm{~h}(P=0.0045)$ clearly demonstrates that this approach can improve the retention of RM26-based GRPR-antagonistic targeting vectors. Pancreatic uptake of the human GRPR-targeted antagonists was minimal at $4 \mathrm{~h}$ because of the well-known clearance of these targeting vectors from the mouse pancreas $(26,27)$. 
TABLE 2

Biodistribution Studies in PC-3 Tumor-Bearing SCID Mice

\begin{tabular}{|c|c|c|c|}
\hline Tissue & $4 \mathrm{~h}$ & $24 \mathrm{~h}$ & $72 \mathrm{~h}$ \\
\hline \multicolumn{4}{|l|}{${ }^{177}$ Lu-E-AG } \\
\hline Blood & $0.07 \pm 0.07$ & $0.02 \pm 0.02$ & $0.01 \pm 0.02$ \\
\hline Liver & $0.44 \pm 0.16$ & $0.46 \pm 0.13$ & $0.42 \pm 0.09$ \\
\hline Pancreas & $41 \pm 12$ & $34 \pm 5$ & $26.3 \pm 1.5$ \\
\hline Stomach & $0.9 \pm 0.5$ & $0.4 \pm 0.2$ & $0.40 \pm 0.06$ \\
\hline Spleen* & $0.017 \pm 0.003$ & $0.04 \pm 0.04$ & $0.03 \pm 0.01$ \\
\hline Small intestine ${ }^{*}$ & $1.9 \pm 0.7$ & $1.73 \pm 0.08$ & $1.13 \pm 0.17$ \\
\hline Kidney & $10 \pm 3$ & $10 \pm 3$ & $7.1 \pm 0.9$ \\
\hline Tumor & $3.3 \pm 1.1$ & $3.0 \pm 0.4$ & $2.06 \pm 0.16$ \\
\hline Muscle & $0.04 \pm 0.06$ & $0.02 \pm 0.02$ & $0.06 \pm 0.06$ \\
\hline Bone & $0.4 \pm 0.3$ & $0.5 \pm 0.2$ & $0.28 \pm 0.09$ \\
\hline \multicolumn{4}{|l|}{${ }^{177} \mathrm{Lu}-\mathrm{C}-\mathrm{AG}$} \\
\hline Blood & $0.02 \pm 0.02$ & $0.03 \pm 0.04$ & $0.01 \pm 0.01$ \\
\hline Liver & $0.22 \pm 0.05$ & $0.18 \pm 0.06$ & $0.10 \pm 0.04$ \\
\hline Pancreas & $41 \pm 18$ & $31 \pm 6$ & $17.6 \pm 0.4$ \\
\hline Stomach & $0.47 \pm 0.11$ & $0.33 \pm 0.02$ & $0.10 \pm 0.03$ \\
\hline Spleen* & $0.05 \pm 0.05$ & $0.03 \pm 0.03$ & $0.10 \pm 0.03$ \\
\hline Small intestine ${ }^{*}$ & $2.1 \pm 0.4$ & $0.86 \pm 0.18$ & $0.40 \pm 0.05$ \\
\hline Kidney & $6 \pm 2$ & $3.8 \pm 1.4$ & $1.09 \pm 0.10$ \\
\hline Tumor & $2.9 \pm 0.4$ & $1.8 \pm 0.3$ & $0.94 \pm 0.14$ \\
\hline Muscle & $0.06 \pm 0.06$ & $0.03 \pm 0.05$ & $0.02 \pm 0.02$ \\
\hline Bone & $0.01 \pm 0.01$ & $0.03 \pm 0.05$ & $0.08 \pm 0.08$ \\
\hline \multicolumn{4}{|l|}{${ }^{177}$ Lu-E-AN } \\
\hline Blood & $0.01 \pm 0.01$ & $0.04 \pm 0.03$ & $0.02 \pm 0.02$ \\
\hline Liver & $0.55 \pm 0.07$ & $0.66 \pm 0.12$ & $0.4 \pm 0.2$ \\
\hline Pancreas & $1.1 \pm 0.3$ & $0.7 \pm 0.5$ & $0.5 \pm 0.2$ \\
\hline Stomach & $0.41 \pm 0.19$ & $0.11 \pm 0.06$ & $0.02 \pm 0.03$ \\
\hline Spleen* & $0.01 \pm 0.02$ & $0.02 \pm 0.02$ & $0.02 \pm 0.01$ \\
\hline Small intestine* & $0.26 \pm 0.13$ & $0.13 \pm 0.02$ & $0.05 \pm 0.03$ \\
\hline Kidney & $7.4 \pm 0.9$ & $6.7 \pm 1.4$ & $3.7 \pm 1.8$ \\
\hline Tumor & $11.9 \pm 1.7$ & $6.3 \pm 0.6$ & $3.8 \pm 0.7$ \\
\hline Muscle & $0.15 \pm 0.14$ & $0.21 \pm 0.18$ & $0.15 \pm 0.17$ \\
\hline Bone & $0.21 \pm 0.16$ & $0.6 \pm 0.2$ & $0.2 \pm 0.3$ \\
\hline \multicolumn{4}{|l|}{${ }^{177}$ Lu-C-AN } \\
\hline Blood & $0.2 \pm 0.2$ & $0.02 \pm 0.03$ & $0.007 \pm 0.004$ \\
\hline Liver & $0.63 \pm 0.18$ & $0.26 \pm 0.14$ & $0.22 \pm 0.05$ \\
\hline Pancreas & $1.5 \pm 1.0$ & $0.4 \pm 0.4$ & $0.10 \pm 0.09$ \\
\hline Stomach & $0.5 \pm 0.4$ & $0.03 \pm 0.03$ & $0.02 \pm 0.03$ \\
\hline Spleen* & $0.02 \pm 0.01$ & $0.02 \pm 0.02$ & $0.01 \pm 0.01$ \\
\hline Small intestine* & $0.26 \pm 0.09$ & $0.08 \pm 0.03$ & $0.02 \pm 0.02$ \\
\hline Kidney & $5.4 \pm 1.7$ & $1.6 \pm 0.4$ & $0.7 \pm 0.2$ \\
\hline Tumor & $13 \pm 3$ & $3.8 \pm 0.5$ & $1.9 \pm 0.5$ \\
\hline Muscle & $0.13 \pm 0.13$ & $0.2 \pm 0.4$ & $0.03 \pm 0.03$ \\
\hline Bone & $0.6 \pm 0.3$ & $0.5 \pm 0.9$ & $0.07 \pm 0.07$ \\
\hline
\end{tabular}

*Data are represented as \%ID.

Data are mean $\% I D / g \pm S D(n \geq 4)$ unless otherwise noted.

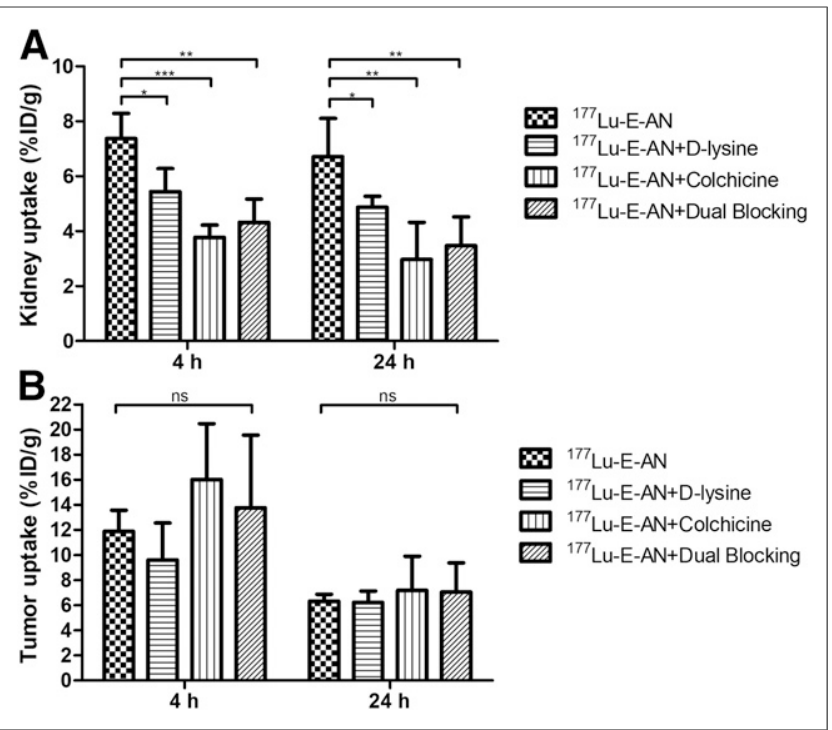

FIGURE 4. (A) Examination of renal blocking agents for ${ }^{177} \mathrm{Lu}-\mathrm{E}-$ AN. (B) Tumor uptake of ${ }^{177} \mathrm{Lu}-\mathrm{E}-\mathrm{AN}$ in presence of different blocking agents.

\section{SPECT/CT Imaging}

On the basis of their higher initial tumor uptake values, ${ }^{177} \mathrm{Lu}-\mathrm{E}-$ $\mathrm{AN}$ and ${ }^{177} \mathrm{Lu}-\mathrm{C}-\mathrm{AN}$ were chosen for follow-up SPECT/CT imaging (Fig. 5). At $4 \mathrm{~h}$, significant uptake was observed in the PC-3 tumors and kidney for both radioconjugates. After $24 \mathrm{~h}$, reductions were seen in both kidney and tumor retention.

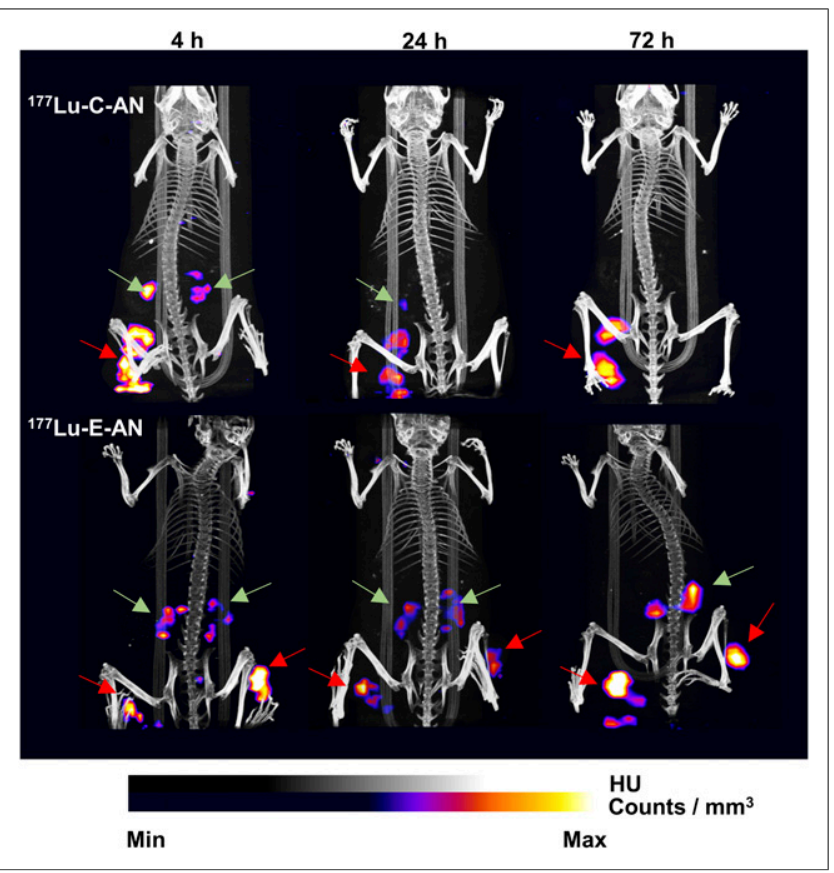

FIGURE 5. Fused small-animal SPECT/CT images of ${ }^{177} \mathrm{Lu}-\mathrm{C}-\mathrm{AN}$ and ${ }^{177} \mathrm{Lu}-\mathrm{E}-\mathrm{AN}$ in PC-3 tumor-bearing mice at 4, 24, and $72 \mathrm{~h}$ after injection. Tumors (red arrows) and kidneys (green arrows) are indicated. For each time point, SPECT/CT images for both radioconjugates were scaled identically. $\mathrm{HU}=$ Hounsfield units; $\mathrm{Min}=$ minimum; Max = maximum. 
By 72 h, ${ }^{177} \mathrm{Lu}-\mathrm{E}-\mathrm{AN}$ demonstrated substantially higher focal accumulation in the PC-3 tumors than did ${ }^{177} \mathrm{Lu}-\mathrm{C}-\mathrm{AN}$. However, ${ }^{177} \mathrm{Lu}-\mathrm{C}-\mathrm{AN}$ exhibited renal retention noticeably lower than that of ${ }^{177} \mathrm{Lu}-\mathrm{E}-\mathrm{AN}$. Overall, the SPECT/CT imaging studies correlated well with results from the biodistribution studies.

\section{Ex Vivo Adduct Studies}

To confirm in vivo adduct formation, all 4 radioconjugates were administered to PC-3 tumor-bearing mice. The tumor, pancreas, liver, and kidney were excised at $24 \mathrm{~h}$ after injection, lysed, and evaluated by SDS-PAGE (Fig. 6). As expected, ${ }^{177} \mathrm{Lu}-\mathrm{C}-\mathrm{AG}$ and ${ }^{177} \mathrm{Lu}-\mathrm{C}-\mathrm{AN}$ presented no bands associated with adduct formation at $24 \mathrm{~h}$ after injection. However, both ${ }^{177} \mathrm{Lu}-\mathrm{E}-\mathrm{AG}$ and ${ }^{177} \mathrm{Lu}-\mathrm{E}-\mathrm{AN}$ revealed adduct formation that ranged roughly from 20 to $32 \mathrm{kDa}$ in molecular weight, but interestingly, the intensities of these bands were tissue-dependent. For ${ }^{177} \mathrm{Lu}-\mathrm{E}-\mathrm{AG}$, strong signals were observed in the tumor, pancreas, and kidneys, whereas ${ }^{177} \mathrm{Lu}-\mathrm{E}-\mathrm{AN}$ gave bands in only the tumor and kidney. Speculatively, this striking difference in pancreas uptake between agonist and antagonist may be due to structural or homology differences between the mouse and human GRPR with regard to binding or activation or to differences in the basal endocytic activity between these cell types. The overall profiles of the bands observed in the tumor and kidney for ${ }^{177} \mathrm{Lu}-\mathrm{E}-\mathrm{AN}$ were similar to those for the corresponding agonist. Centrifugal filtration studies demonstrated that $79.0 \% \pm$ $0.6 \%$ and $76 \% \pm 4 \%$ of the radioactivity resident in the tumor lysates was associated with macromolecules for ${ }^{177} \mathrm{Lu}-\mathrm{E}-\mathrm{AG}$ and ${ }^{177} \mathrm{Lu}-\mathrm{E}-\mathrm{AN}$, respectively. These percentages were substantially

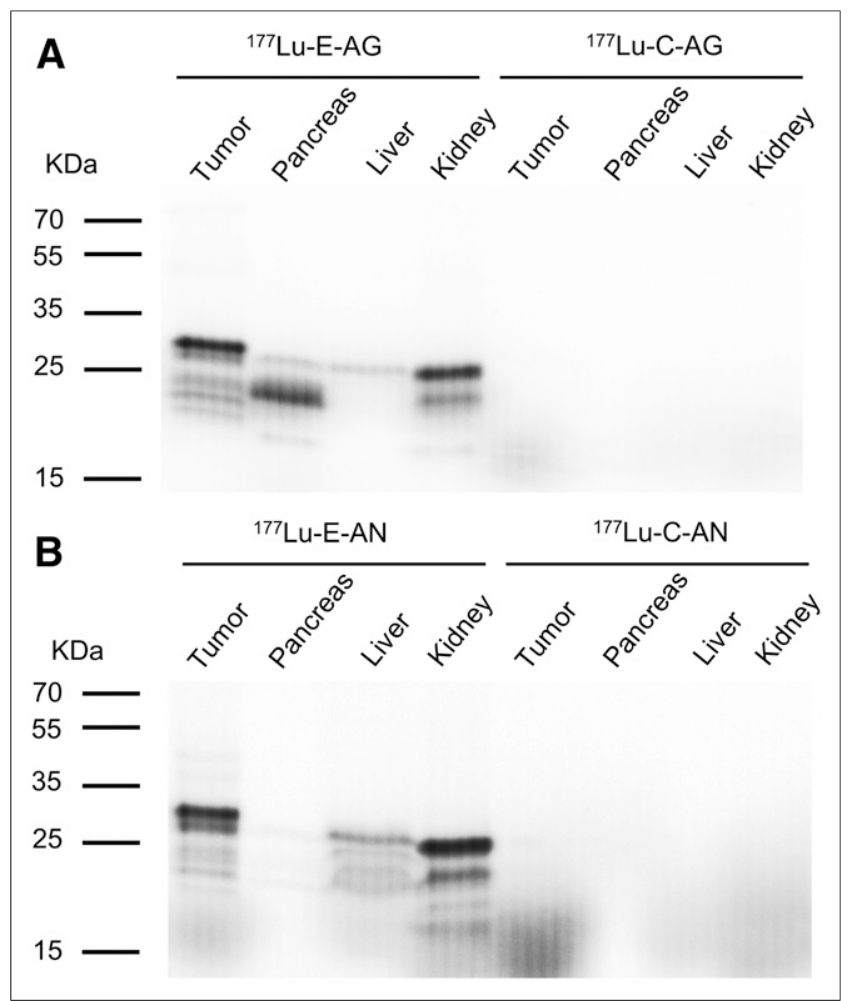

FIGURE 6. Autoradiograph of SDS-PAGE gel for lysates from PC-3 tumors, liver, pancreas, and kidney at $24 \mathrm{~h}$ after injection. (A) ${ }^{177} \mathrm{Lu}-\mathrm{E}-$ AG and ${ }^{177}$ Lu-C-AG. (B) ${ }^{177}$ Lu-E-AN and ${ }^{177}$ Lu-C-AN. higher than the respective $8 \% \pm 3 \%$ and $57 \% \pm 4 \%$ for the corresponding control conjugates and consistent with previous in vitro results.

\section{DISCUSSION}

Despite the success of GRPR- and other receptor-targeted agents, the inherently higher diffusion and metabolic rates of low-molecular-weight agents often lead to tumor clearance, which diminishes the effectiveness of the resulting diagnostic or therapeutic agent. To address this challenge, our laboratory has recently begun exploring the use of $\mathrm{CC}$ inhibitors to enhance the long-term retention of receptor-targeted agents $(13,14)$. Mechanistically, we have demonstrated that these inhibitors are able to form adducts within the CC-rich, endolysosomal compartments after receptor-mediated internalization. However, the efficacy of this endolysosomal trapping approach for antagonistic analogs with no or limited internalization capabilities was unknown. With this in mind, we decided to explore this tumor residualizing approach using agonistic and antagonistic GRPRtargeted analogs.

As expected, internalization of the agonists, ${ }^{177} \mathrm{Lu}-\mathrm{E}-\mathrm{AG}$ and ${ }^{177} \mathrm{Lu}-\mathrm{C}-\mathrm{AG}$, proceeded rapidly and was more efficient than that of the antagonists, ${ }^{177} \mathrm{Lu}-\mathrm{E}-\mathrm{AN}$ and ${ }^{177} \mathrm{Lu}-\mathrm{C}-\mathrm{AN}$. The surfacebound activity for the antagonists was substantially higher than the internalization, a finding that is consistent with the literature $(28,29)$. Both the agonistic and the antagonistic radioconjugates containing the active $\mathrm{CC}$ inhibitor showed significantly higher retention in the efflux studies, speculatively due to endolysosomal trapping on internalization. Using confocal microscopy, the Europium-labeled agonists demonstrated receptor-mediated internalization into the CC-rich endolysosomal compartments of the cell. Over 24 h, Eu-E-AG revealed significantly increased intracellular retention in the $\mathrm{CC}$-rich, endolysosomal compartments relative to $\mathrm{Eu}-\mathrm{C}-\mathrm{AG}$, a finding that is consistent with our premise of adduct formation with $\mathrm{CCs}$ upon receptor-mediated endocytosis.

The ability of active endolysosomal trapping conjugates to form adducts with CatB and within PC-3 cells was confirmed by SDSPAGE, whereas the inactive control conjugates, as expected, showed no adduct formation. Blocking the GRPR with an excess of unlabeled agonist or antagonist prevented the active endolysosomal trapping conjugates from forming $\mathrm{CC}$ adducts. The agonist demonstrated the highest adduct formation early on ( 2 and $4 \mathrm{~h}$ ), but the adduct signal diminished significantly by $24 \mathrm{~h}$. We attribute this decline to the protein turnover (degradation) of CCs, and their adducts, in the endolysosomal compartments. Interestingly, the concentration of adducts for ${ }^{177} \mathrm{Lu}-\mathrm{E}-\mathrm{AN}$ increased over $24 \mathrm{~h}$, almost certainly because of a steady rate of internalization of the surface-bound radioactivity. Mansi et al. hypothesized that these antagonistic targeting vectors undergo slow internalization (8). Our results lend further credence to this postulation and suggest that this particular antagonistic targeting vector may be better thought of as a slowly internalizing instead of a noninternalizing construct.

The biodistribution studies verified that all radioconjugates provided good blood and muscle clearance, demonstrating that the used CC inhibitor is stable in vivo. PC-3 tumor uptake at $4 \mathrm{~h}$ after injection for the RM26-based antagonists was approximately 3to 4-fold higher than that for the agonists, as is consistent with other reports $(8,30)$. For both the agonistic and the antagonistic 
targeting vectors, use of active endolysosomal trapping agents led to significantly higher levels (2-fold) of retention relative to analogous controls. The ex vivo examination of the PC-3 tumors by centrifugal filtration at $24 \mathrm{~h}$ after administration revealed that for both ${ }^{177} \mathrm{Lu}-\mathrm{E}-\mathrm{AG}$ and ${ }^{177} \mathrm{Lu}-\mathrm{E}-\mathrm{AN}$, greater than $70 \%$ of the radioactivity was associated with macromolecules. SDS-PAGE demonstrated that in vivo tumor adduct formation profiles for both active endolysosomal trapping radioconjugates were identical. Although the contribution of the extracellular CCs to adduct formation cannot be discounted (31), our in vitro data and the similar ex vivo SDS-PAGE adduct profiles for the agonist and antagonist would, in our opinion, argue that internalization was the primary route of in vivo adduct formation in the tumor.

For both the agonists and the antagonists, the endolysosomal trapping approach increased renal retention. This increase in renal retention for the radioconjugates with the active trapping agent is almost certainly due to the well-known uptake mechanisms of the kidney (32), leading to adduct formation and higher retention in the renal proximal tubules. Thus, we examined different blocking agents to inhibit the renal uptake of ${ }^{177} \mathrm{Lu}-\mathrm{E}-\mathrm{AN}$. Overall, our data demonstrated the feasibility of using known blocking agents to decrease renal absorption of ${ }^{177} \mathrm{Lu}-\mathrm{E}-\mathrm{AN}$ without compromising tumor uptake.

\section{CONCLUSION}

This study examined the potential of a $\mathrm{CC}$ inhibitor to act as an endolysosomal trapping agent to improve the tumor retention of GRPR-targeted agents. Specifically, a hydrophilic CC inhibitor, based on the well-known E-64, was incorporated into both agonistic (BBN(7-14) $\mathrm{NH}_{2}$ ) and antagonistic (RM26) GRPR-targeted constructs. Incorporation of the $\mathrm{CC}$ inhibitor into the pharmacophores did not substantially affect either the CC inhibition potency of the inhibitor or the GRPR affinity of the peptide. For both the agonistic and the antagonistic analogs, in vitro studies demonstrated that the $\mathrm{CC}$ inhibitors prompted the formation of $\mathrm{CC}$ adducts when internalized into GRPR-positive PC-3 prostate cancer cells. In vivo studies clearly demonstrated macromolecular adduct formation and a substantial increase (approximately 2-fold) in tumor residualization for the CC-trapping, GRPR-targeted agents. Overall, these data demonstrate the potential of the $\mathrm{CC}$ endolysosomal trapping approach to enhance both agonistic and antagonistic GRPR-targeted agent development. When considered in context with our previously published work concerning CC-trapping, NTSR1-targeted agents, this technique, in our opinion, could have broad applicability to enhance targeted drug development.

\section{DISCLOSURE}

This study was supported by the National Institutes of Health (5R01CA179059-04). No other potential conflict of interest relevant to this article was reported.

\section{ACKNOWLEDGMENTS}

We thank Janice A. Taylor and James R. Talaska of the Advanced Microscopy Core Facility at the University of Nebraska Medical Center (UNMC) for providing assistance with confocal microscopy. We also thank Dr. Vikas Kumar of the Mass
Spectrometry and Proteomics Core at UNMC for help with high resolution mass spectrometry (HRMS) acquisition. We thank Dr. Howard E. Gendelman for assistance with SPECT/CT acquisition and for editing the manuscript.

\section{KEY POINTS}

QUESTION: Can CC inhibitors be used to increase the tumor residualization and clinical potential of receptor-targeted radiopharmaceuticals?

PERTINENT FINDINGS: By using the irreversible CC inhibitor as a trapping agent, we demonstrated substantial enhancement in the in vivo tumor retention of agonistic and antagonistic GRPR-targeted constructs. This increased and selective retention is due to adduct formation with cysteine proteases resulting in a 2-fold improvement in tumor residualization over $72 \mathrm{~h}$.

IMPLICATIONS FOR PATIENT CARE: This approach may provide a pathway to increase the clinical potential of receptor-targeted constructs for diagnostic and, especially, radiotherapeutic purposes.

\section{REFERENCES}

1. Mansi R, Fleischmann A, Macke HR, Reubi JC. Targeting GRPR in urological cancers: from basic research to clinical application. Nat Rev Urol. 2013;10:235-244.

2. Yu Z, Ananias HJ, Carlucci G, et al. An update of radiolabeled bombesin analogs for gastrin-releasing peptide receptor targeting. Curr Pharm Des. 2013;19:33293341 .

3. Smith CJ, Volkert WA, Hoffman TJ. Radiolabeled peptide conjugates for targeting of the bombesin receptor superfamily subtypes. Nucl Med Biol. 2005;32: 733-740.

4. Baratto L, Jadvar H, Iagaru A. Prostate cancer theranostics targeting gastrinreleasing peptide receptors. Mol Imaging Biol. 2018;20:501-509.

5. Tokita K, Hocart SJ, Coy DH, Jensen RT. Molecular basis of the selectivity of gastrin-releasing peptide receptor for gastrin-releasing peptide. Mol Pharmacol. 2002;61:1435-1443.

6. Cescato R, Maina T, Nock B, et al. Bombesin receptor antagonists may be preferable to agonists for tumor targeting. J Nucl Med. 2008;49:318-326.

7. Cheng S, Lang L, Wang Z, et al. Positron emission tomography imaging of prostate cancer with Ga-68-labeled gastrin-releasing peptide receptor agonist BBN $_{7-14}$ and antagonist RM26. Bioconjug Chem. 2018;29:410-419.

8. Mansi R, Wang X, Forrer F, et al. Evaluation of a 1,4,7,10-tetraazacyclododecane-1,4,7,10-tetraacetic acid-conjugated bombesin-based radioantagonist for the labeling with single-photon emission computed tomography, positron emission tomography, and therapeutic radionuclides. Clin Cancer Res. 2009;15:5240-5249.

9. Nanda PK, Wienhoff BE, Rold TL, et al. Positron-emission tomography (PET) imaging agents for diagnosis of human prostate cancer: agonist vs. antagonist ligands. In Vivo. 2012;26:583-592.

10. Minamimoto R, Hancock S, Schneider B, et al. Pilot comparison of ${ }^{68} \mathrm{Ga}-\mathrm{RM} 2$ PET and ${ }^{68}$ Ga-PSMA-11 PET in patients with biochemically recurrent prostate cancer. J Nucl Med. 2016;57:557-562.

11. Wieser G, Popp I, Christian Rischke H, et al. Diagnosis of recurrent prostate cancer with PET/CT imaging using the gastrin-releasing peptide receptor antagonist ${ }^{68} \mathrm{Ga}-\mathrm{RM} 2$ : preliminary results in patients with negative or inconclusive $\left[{ }^{18} \mathrm{~F}\right]$ fluoroethylcholine-PET/CT. Eur J Nucl Med Mol Imaging. 2017;44:1463-1472.

12. Grudzinski JJ, Burnette RR, Weichert JP, Jeraj R. Dosimetric effectiveness of targeted radionuclide therapy based on a pharmacokinetic landscape. Cancer Biother Radiopharm. 2010;25:417-426.

13. Fan W, Zhang W, Alshehri S, Garrison JC. Increasing time on target: utilization of inhibitors of cysteine cathepsins to enhance the tumor retention of receptortargeted agents. Chem Commun (Camb). 2018;54:11268-11271.

14. Fan W, Zhang W, Alshehri S, Neeley TR, Garrison JC. Enhanced tumor retention of NTSR1-targeted agents by employing a hydrophilic cysteine cathepsin inhibitor. Eur J Med Chem. 2019;177:386-400.

15. Chen K, Xie J, Chen X. RGD-human serum albumin conjugates as efficient tumor targeting probes. Mol Imaging. 2009;8:65-73.

16. Janssen M, Oyen WJ, Massuger LF, et al. Comparison of a monomeric and dimeric radiolabeled RGD-peptide for tumor targeting. Cancer Biother Radiopharm. 2002;17:641-646. 
17. Reinheckel T, Deussing J, Roth W, Peters C. Towards specific functions of lysosomal cysteine peptidases: phenotypes of mice deficient for cathepsin B or cathepsin L. Biol Chem. 2001;382:735-741.

18. Joyce JA, Baruch A, Chehade K, et al. Cathepsin cysteine proteases are effectors of invasive growth and angiogenesis during multistage tumorigenesis. Cancer Cell. 2004;5:443-453.

19. Vasiljeva O, Reinheckel T, Peters C, Turk D, Turk V, Turk B. Emerging roles of cysteine cathepsins in disease and their potential as drug targets. Curr Pharm Des. 2007;13:387-403.

20. Otto HH, Schirmeister T. Cysteine proteases and their inhibitors. Chem Rev. 1997;97:133-172.

21. Wagh NK, Zhou Z, Ogbomo SM, Shi W, Brusnahan SK, Garrison JC. Development of hypoxia enhanced ${ }^{111} \mathrm{In}$-labeled bombesin conjugates: design, synthesis, and in vitro evaluation in PC-3 human prostate cancer. Bioconjug Chem. 2012; 23:527-537.

22. Zhou Z, Wagh NK, Ogbomo SM, et al. Synthesis and in vitro and in vivo evaluation of hypoxia-enhanced ${ }^{111} \mathrm{In}$-bombesin conjugates for prostate cancer imaging. J Nucl Med. 2013;54:1605-1612.

23. Garrison JC, Rold TL, Sieckman GL, et al. Evaluation of the pharmacokinetic effects of various linking group using the ${ }^{111}$ In-DOTA-X-BBN(7-14) $\mathrm{NH}_{2}$ structural paradigm in a prostate cancer model. Bioconjug Chem. 2008;19:18031812.

24. Rolleman EJ, Krenning EP, Van Gameren A, Bernard BF, De Jong M. Uptake of $\left[{ }^{111}\right.$ In-DTPA0] octreotide in the rat kidney is inhibited by colchicine and not by fructose. J Nucl Med. 2004;45:709-713.
25. Huang SC, Yu DH, Wank SA, Gardner JD, Jensen RT. Characterization of the bombesin receptor on mouse pancreatic acini by chemical cross-linking. Peptides. 1990;11:1143-1150.

26. Mansi R, Wang X, Forrer F, et al. Development of a potent DOTA-conjugated bombesin antagonist for targeting GRPr-positive tumours. Eur J Nucl Med Mol Imaging. 2011;38:97-107.

27. Varasteh Z, Velikyan I, Lindeberg G, et al. Synthesis and characterization of a high-affinity NOTA-conjugated bombesin antagonist for GRPR-targeted tumor imaging. Bioconjug Chem. 2013;24:1144-1153.

28. Zhuo L, Yang X, Liao W, et al. Comparative cell uptake study of FITC-/ ${ }^{177} \mathrm{Lu}-$ labeled RM26 monomer, dimer and trimer on PC-3: improving binding affinity of gastrin releasing peptide receptor (GRPR) antagonist via bivalency/trivalency. J Radioanal Nucl Chem. 2019;319:881-889.

29. Varasteh Z, Rosenstrom U, Velikyan I, et al. The effect of mini-PEG-based spacer length on binding and pharmacokinetic properties of a ${ }^{68} \mathrm{Ga}$-labeled NOTA-conjugated antagonistic analog of bombesin. Molecules. 2014;19:1045510472.

30. Liu Y, Hu X, Liu H, et al. A comparative study of radiolabeled bombesin analogs for the PET imaging of prostate cancer. J Nucl Med. 2013;54:21322138 .

31. Fonović M, Turk B. Cysteine cathepsins and extracellular matrix degradation. Biochim Biophys Acta. 2014;1840:2560-2570.

32. Vegt E, Melis M, Eek A, et al. Renal uptake of different radiolabelled peptides is mediated by megalin: SPECT and biodistribution studies in megalin-deficient mice. Eur J Nucl Med Mol Imaging. 2011;38:623-632. 